\title{
Verbal Memory in Parkinson's Disease: A Combined DTI and fMRI Study
}

\author{
Olaia Lucas-Jiménez ${ }^{\mathrm{a}}$, María Díez-Cirarda ${ }^{\mathrm{a}}$, Natalia Ojeda ${ }^{\mathrm{a}}$, Javier Peña ${ }^{\mathrm{a}}$, \\ Alberto Cabrera-Zubizarreta ${ }^{\mathrm{b}}$ and Naroa Ibarretxe-Bilbao ${ }^{\mathrm{a}, *}$ \\ ${ }^{a}$ Department of Methods and Experimental Psychology, Faculty of Psychology and Education, \\ University of Deusto, Bilbao, Basque Country, Spain \\ ${ }^{\mathrm{b}}$ OSATEK, MR Unit, Hospital of Galdakao, Galdakao, Basque Country, Spain
}

\begin{abstract}
.
Background: While significant progress has been made to determine the functional role of specific gray matter areas underlying verbal memory in Parkinson's disease (PD), very little is known about the relationship between these regions and their underlying white matter structures.

Objective: The objectives of this study were (1) to investigate verbal memory, fractional anisotropy and brain activation differences between PD patients and healthy controls (HC), (2) to explore the neuroanatomical and neurofunctional correlates of verbal memory in $\mathrm{PD}$, and (3) to investigate the relationship between these neuroanatomical and neurofunctional verbal memory correlates in PD.

Methods: Functional magnetic resonance imaging (fMRI) while performing a verbal memory paradigm and diffusion tensor imaging data (DTI), were acquired in 37 PD patients and 15 age-, sex-, and education-matched HC.

Results: PD patients showed verbal recognition memory impairment, lower fractional anisotropy in the anterior cingulate tract, and lower brain activation in the inferior orbitofrontal cortex compared to HC. Brain activation in the inferior orbitofrontal cortex correlated significantly with verbal recognition memory impairment in PD patients. In addition, a relationship between brain activation in the inferior orbitofrontal cortex and fractional anisotropy of the uncinate fasciculus was found in PD.

Conclusions: These results reveal that deficits in verbal memory in PD are accompanied by functional brain activation changes, but also have specific structural correlates related to white matter microstructural integrity.
\end{abstract}

Keywords: Parkinson's disease, DTI, fMRI, verbal memory, recognition, learning

\section{INTRODUCTION}

Parkinson's disease (PD) is one of the most common neurodegenerative diseases worldwide. It is characterized by motor symptoms and is associated with brain atrophy [1]. Cognitive dysfunction is present in PD from the early stages of the disease and often ends in dementia $[2,3]$. PD patients show several neurocognitive deficits, including deficits in executive functioning, visuo-spatial abilities, and memory [4-9].

Whereas executive dysfunction has been thought of as the hallmark cognitive deficit in PD [10], memory impairment has recently been found as the most com-

\footnotetext{
${ }^{*}$ Correspondence to: Dr. Naroa Ibarretxe-Bilbao, Faculty of Psychology and Education. University of Deusto, Avda Universidades 24, (48007), Bilbao, Spain. Tel.: +34 944139 000/Ext.: 2892; E-mail: naroa.ibarretxe@deusto.es.
}

mon deficit [8]. Moreover, verbal memory impairment has the largest effect size in comparison with other cognitive domains [8, 11-14]. Traditionally, it has been suggested that PD patients have impaired recall but recognition memory remains relatively intact [15-17]. However, some studies report that memory impairments in PD are not solely due to retrieval problems and show evidence of recognition memory deficit in PD patients $[14,15,18,19]$. In addition, recognition memory deficits in PD may result partially from the impairment of learning or encoding process $[14,18-21]$ related to frontal lobe dysfunction $[22,23]$. It may also be caused by the presence of frontal [22] and medial temporal regions dysfunction [13, 24]. Recognition memory comprises two independent processes, recollective and familiarity detection, both processes involve medial temporal regions [25-28]. 
Structural connectivity can be investigated with diffusion tensor imaging (DTI). Fractional anisotropy (FA) is a DTI index that assesses the fiber integrity of a tract. DTI studies have revealed widespread white matter (WM) FA reduction in PD patients compared to healthy controls (HC) from the early stages of the disease [29, 30] through dementia [31, 32]. Although a number of DTI studies have been conducted to better understand PD pathology, only a few studies have focused on the relationship between DTI FA and cognitive deficits in PD [30, 33-35]. Global cognitive impairment has been associated with WM microstructural FA changes in PD [36, 37], and specific cognitive impairments, such as executive functioning, attention and visuospatial ability, it also appears to be associated with WM microstructural FA changes in PD [30, 33, 34]. Nevertheless, little is known about the DTI FA correlates of verbal memory in PD.

Functional magnetic resonance imaging (fMRI) studies in early PD have investigated neural circuitry of motor symptoms of the disease [38, 39]. However, regarding cognitive performance, studies are scarce and have primarily focused on the assessment of brain activity related to impaired executive functions [40,41] and on the dysfunction of the default mode network in PD $[42,43]$. The few cognitive fMRI studies published using a memory task have revealed alterations in memory networks $[12,43]$. In the study of Ibarretxe-Bilbao et al., [43] and in the longitudinal follow-up [12], PD patients showed less task-related activation than $\mathrm{HC}$ in areas involved in the recognition memory network, including less activation in the orbitofrontal cortices, middle frontal gyri, frontal poles, anterior paracingulate cortex, superior parietal lobes, and left middle temporal gyrus.

Although significant progress has been made to determine the functional role of specific gray matter areas that underlie verbal memory in PD, little is known about the relationship between the brain activation of these regions and their connection through WM tracts. To date, no combined structural and functional MRI study has focused on the neural correlates of verbal memory in PD. Therefore, the first objective of this study was to investigate verbal memory, FA and brain activation differences between PD patients and HC. The secondary goal was to explore the neuroanatomical and neurofunctional underpinnings of verbal memory in PD. Finally, the third aim was to investigate the relationship between these neuroanatomical and neurofunctional verbal memory correlates in PD.
For the first objective, we hypothesized that PD patients would perform worse in the verbal memory fMRI paradigm, would have less WM FA, and lower functional brain activation during fMRI paradigm compared to HC. Verbal learning and recognition memory is related to the frontal and medial temporal regions [11, 43, 44]. Hence, for the second objective we hypothesized that the verbal memory fMRI paradigm would be related to functional brain activity in the frontal and temporal regions and to the FA in the WM tracts adjacent to those regions in PD. Finally, for the third goal, we hypothesized that there would be an association between the WM microstructure FA and functional brain activation in those frontal and temporal regions.

\section{MATERIALS AND METHODS}

\section{Participants}

The sample included 37 PD patients recruited from the Department of Neurology at the Galdakao Hospital (Galdakao, Spain) and from the PD Biscay Association (ASPARBI). The main purpose of the study was to analyze the neural bases of verbal memory deficit in PD; however, we also included $15 \mathrm{HC}$, recruited by acquaintances of the patients, matched with the patients by age, gender, and years of education, to assess differences between groups. A neurologist specialized in movement disorders made the diagnosis of PD based on the UK PD Society Brain Bank diagnostic criteria. Other inclusion criteria were (1) age 45 to 75 and (2) an evaluation conducted by a neurologist in accordance with the Hoehn \& Yahr disease stages and Unified PD Rating Scale (UPDRS). Exclusion criteria were as follows: (1) the presence of dementia, as defined by the Diagnostic and Statistical Manual of Mental Disorders, Fourth Edition, Text Revision (DSM-IV-TR) and the International Parkinson and Movement Disorder Society clinical criteria for PD dementia (PDD); (2) the presence of other neurological illness or injury (e.g., traumatic brain injury or multiple sclerosis); (3) stable psychiatric disorders (e.g., schizophrenia); (4) depression measured by Geriatric Depression Scale $>5$ and (5) visual hallucinations, as assessed by the Neuropsychiatric Inventory Questionnaire. One patient was taking no medication and 36 were on anti-Parkinsonian treatment as follows: Levodopa (L-dopa) monotherapy $(n=4)$, combination of L-dopa and dopamine agonist $(n=5)$, monoamine oxidase type B (MAO-B) inhibitors monotherapy 
$(n=1)$, combination of L-dopa and MAO-B $(n=5)$, combination of L-dopa, dopamine agonist and MAO-B $(n=9)$, combination of dopamine agonist and MAO-B $(n=4)$, combination of dopamine agonist and anticholinergics $(n=2)$, combination of glutamate agonists in combination with others $(n=4)$, and catechol-Omethyltransferase (COMT) inhibitors in combination with others $(n=2)$. Participants were symptomatically stable and tested while on their medication. Their L-dopa equivalent daily dose was registered [45]. The motor deficit in the PD group was largely mild (Hoehn \& Yahr staging: stage 1:13.5\%; stage 1.5:8.1\%; stage 2:70.3\%; stage $2.5: 2.7 \%$; and stage $3: 5.4 \%$ ). The clinical and sociodemographic characteristics of the sample are shown in Table 1.

\section{Verbal memory fMRI paradigm}

Verbal memory was assessed by an fMRI paradigm. The paradigm consisted of words presented inside a $3 \mathrm{~T}$ magnet with Visual Digital MRI Compatible High Resolution Stereo 3D glasses and Presentation ${ }^{\circledR}$ version 10.1 (Neurobehavioral Systems), running on Windows XP. They were also given two controls (one in each hand) connected to a MR-compatible response box to record/register their responses. The entire experiment consisted of a 10-block paradigm (learning and recognition tasks) that alternated activation and control conditions ( 5 blocks each) and lasted a total of $280 \mathrm{~s}$ ( $28 \mathrm{~s}$ per block). In the learning memory fMRI task, participants viewed 30 words (with a duration of $2 \mathrm{~s}$ per word and inter-word intervals of $1 \mathrm{~s}$ ) and were asked to press the right button (with their right hand) if they liked the word or the left button (with their left hand) if they did not like the word; this was done to make sure they were reading the words (activation condition). Moreover, six concatenations of letters were projected (simulating the length of a word) of which three were the letters "AAAAAA" and the other three were random letters (control condition). A review of 4 experiments confirms that this paradigm is effective

Table 1

Socio-demographic, clinical and neurological characteristics of the sample

\begin{tabular}{|c|c|c|c|c|}
\hline & $\mathrm{PD}(n=37)$ & $\mathrm{HC}(n=15)$ & Statistic & $p$ \\
\hline Age & $67.97(6.17)$ & $65.07(7.01)$ & $\mathrm{t}=1.479$ & 0.146 \\
\hline Gender (Male) & $22(59.5 \%)$ & $11(73.3 \%)$ & $X^{2}=0.886$ & 0.526 \\
\hline Years of education & $10.24(4.81)$ & $12.27(4.30)$ & $\mathrm{t}=-1.415$ & 0.163 \\
\hline \multicolumn{5}{|l|}{ Marital State } \\
\hline Married & $30(81.1 \%)$ & $13(86.7 \%)$ & $X^{2}=3.635$ & 0.304 \\
\hline Single & $1(2.7 \%)$ & $0 \%$ & & \\
\hline Widowed & $6(16.2 \%)$ & $1(6.7 \%)$ & & \\
\hline Divorced & $0 \%$ & $1(6.7 \%)$ & & \\
\hline \multicolumn{5}{|l|}{ Handedness } \\
\hline Right handed & $33(89.2 \%)$ & $15(100 \%)$ & $X^{2}=1.757$ & 0.311 \\
\hline Ambidextrous & $4(10.8 \%)$ & $0 \%$ & & \\
\hline Geriatric Depression Scale & $2.57(2.80)$ & $1.20(1.37)$ & $\mathrm{t}=1.796$ & 0.079 \\
\hline Neuropsychiatric Inventory & $3.46(4.07)$ & - & - & - \\
\hline \multicolumn{5}{|l|}{ Side of disease onset } \\
\hline Right side of the body & $14(37.8 \%)$ & - & - & - \\
\hline Left side of the body & $21(56.8 \%)$ & - & & \\
\hline \multicolumn{5}{|l|}{ UPDRS } \\
\hline Mental State & $1.86(1.47)$ & - & - & - \\
\hline Daily Living Activities & $10.28(6.27)$ & - & - & - \\
\hline Motor Exam & $21.72(10.29)$ & - & - & - \\
\hline Treatment complications & $2.75(2.88)$ & - & - & - \\
\hline Total Score & $36.61(17.27)$ & - & - & - \\
\hline LEDD & $808.59(536.81)$ & - & - & - \\
\hline Years of Disease Evolution & $6.96(5.61)$ & - & - & - \\
\hline Hoehn \& Yahr & $1.89(0.45)$ & - & - & - \\
\hline Stage 1 & $5(13.5 \%)$ & - & - & - \\
\hline Stage 1.5 & $3(8.1 \%)$ & - & - & - \\
\hline Stage 2 & $26(70.3 \%)$ & - & - & - \\
\hline Stage 2.5 & $1(2.7 \%)$ & - & - & - \\
\hline Stage 3 & $2(5.4 \%)$ & - & - & - \\
\hline
\end{tabular}

Values are expressed as the mean (SD) unless otherwise noted. PD = Parkinson's disease; HC = Healthy controls; SD = Standard Deviation; UPDRS = Unified Parkinson Disease Rating Scale; LEDD = Levodopa Equivalent Daily Dose. 
as a control condition for posterior recognition [46]. After 20 minutes, in the activation condition of the recognition memory fMRI task, subjects were asked to recognize these 15 words during the fMRI scanning from a list of 30 words (15 previously presented words and 15 new words). They viewed six words in each block, of which three had been previously presented. They were tasked to press the button using their right hand to if they remembered having read the word in the list before scanning. However, if they thought that the word in the screen was new, they were asked to press the left button. They were encouraged to respond while the word was on the screen $(2 \mathrm{~s})$. Responses given outside this interval were excluded from the analysis. In the control condition of the recognition memory fMRI task, participants were asked to press the right button on the response box to indicate that the item was "AAAAAA" and press the left button when other concatenations of letters appeared [43]. Responses given with two controls connected to the MR response box, during verbal memory fMRI paradigm, were coded as behavioral data. Hits were recorded when they answered yes when it was yes, correct rejections, when they answered no when it was not, false negatives, when they answered no when it was yes, and false positives, when they answered yes when it was not. For this research only responses during verbal recognition memory task were coded.

\section{Neuroimaging acquisition and analysis}

\section{Diffusion tensor imaging}

DTI was obtained on a Phillips 3T Achieva TX, in an axial orientation in an anterior-posterior phase direction using a single-shot EPI sequence $(\mathrm{TR}=7540$ and $\mathrm{TE}=76$, flip angle $=90^{\circ}, \mathrm{FOV}=240 \times 240 \times 132$, slice thickness $=2 \mathrm{~mm}$, no gap, 66 slices, acquisition time $=9$ ' 31 ", , voxel size $=1.67 \times 1.67 \times 2.0$ ) with diffusion weighting in 32 uniformly distributed directions $(b=1,000 \mathrm{~s} / \mathrm{mm} 2)$ and $1 b=0 \mathrm{~s} / \mathrm{mm} 2$. Voxel-wise statistical analysis of the FA data was carried out using Tract-Based Spatial Statistics [47] part of FSL Software 4.0 [48]. First, each subject' images were concatenated, radiologically oriented, and corrected for eddy current. Then, brain-extraction BET was performed, and all FA images were created by fitting a tensor model to the raw diffusion data using FDT (DTIFIT). All subjects' FA data were then aligned into a common space using the nonlinear registration tool FNIRT. Specific WM tracts have been previously associated with learning and recognition [49-53]; hence, the selected regions of interests (ROI) FA tracts based on JHU white-matter Tractography atlas (http://fsl.fmrib.ox.ac.uk/fsl/fslwiki/Atlases) [54] were: (1) uncinate fasciculus (UF), (2) posterior cingulate tract (PCT), and (3) anterior cingulate tract (ACT) (see Figure 1).

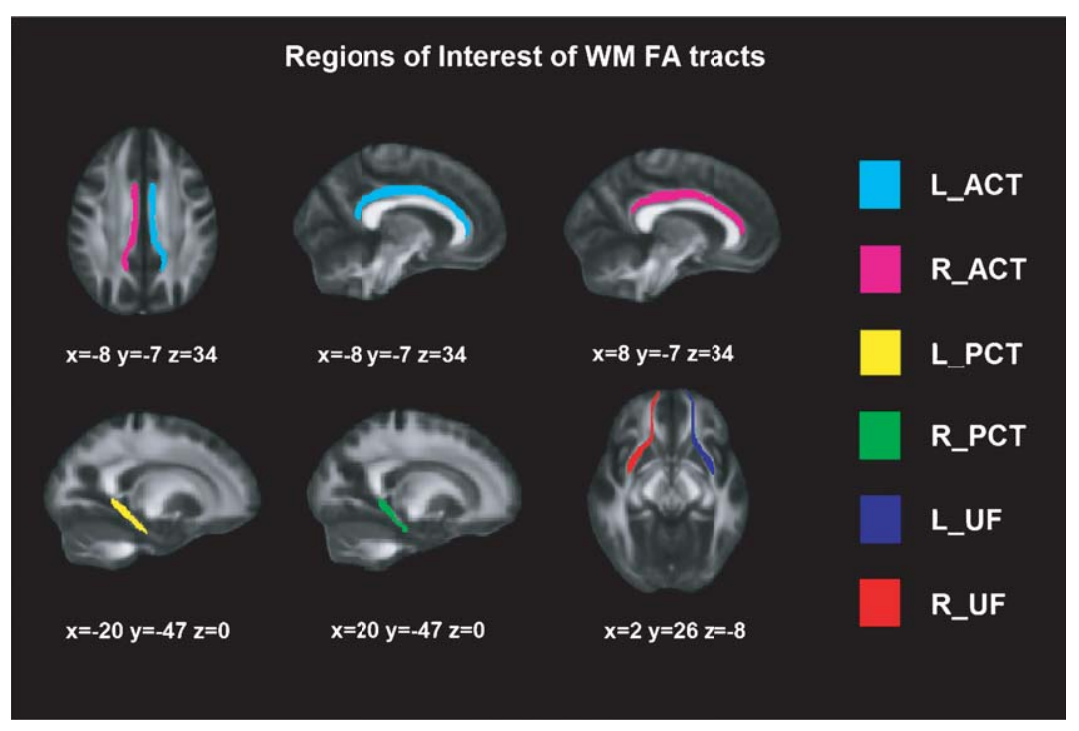

Fig. 1. Regions of Interest of WM FA tracts. Montreal Neurological Institutes (MNI) template coordinates based on JHU WM Tractography Atlas. WM = White Matter; FA = Fractional Anisotropy; L = Left; R = Right; ACT = Anterior Cingulate Tract; PCT = Posterior Cingulate Tract; $\mathrm{UF}=$ Uncinate Fasciculus. 


\section{Functional MRI}

The fMRI was acquired in the same session as the DTI, using multi-slice gradient echo EPI sequence $\left(\mathrm{TR}=2000\right.$ and $\mathrm{TE}=29$, flip angle $=90^{\circ}$, $\mathrm{FOV}=240 \times 240 \times 136$ slice thickness $=3 \mathrm{~mm}, 36$ slices, acquisition time $=4$ '48'). A T1-weighted scan was also acquired $(\mathrm{TR}=7.4$ and $\mathrm{TE}=3.4$, flip angle $=9^{\circ}$, FOV $=250 \times 250 \times 180$, slice thickness $=1.1 \mathrm{~mm}, 300$ slices, acquisition time $=4$ '55", voxel size $=0.98 \times 0.98 \times 0.6)$. The functional data of each participant was motion-corrected, spatially coregistered, and normalized with structural data and smoothed using a Gaussian kernel of $8 \mathrm{~mm}$ FWMH. fMRI beta values (brain activation > contrast) were extracted from each anatomically defined bilateral ROI using the Anatomical Automatic Labelling (AAL) atlas and the MarsBar toolbox (http://marsbar.sourceforge.net/) [55, 56] for both learning and recognition tasks. As outlined in the introduction, the ROIs were selected based on previous findings in learning and recognition assessment in PD [12, 44, 53, 57, 58]. The selected ROIs were: (1) inferior orbitofrontal cortex (IOFC) and (2) medial temporal lobe (MTL) (see Figure 2).

\section{Statistical analysis}

The Shapiro-Wilk test was used to assess the distribution of the data. Independent-samples $t$-tests were conducted to analyze the differences in the clinical and socio-demographic variables between PD patients and HC. Behavioral data and brain activation from the verbal recognition memory fMRI task were not normally distributed. Therefore, Mann-Whitney U test was used to examine differences between PD and $\mathrm{HC}$ groups on those variables. To assess differences in FA and brain activation from the verbal learning memory fMRI task independent-samples $t$-tests were conducted. Analyses were corrected for multiple comparisons with Bonferroni correction.

Partial non-parametric correlations [59] were conducted to investigate all correlations in PD patients controlling for disease stage and disease duration. For HC group, Spearman's Rho tests were conducted to assess correlations between behavioral data from the verbal recognition memory fMRI task and FA and brain activation from the verbal learning and recognition memory fMRI tasks. Finally, for normally distributed variables in HC group, Pearson's product-moment correlations were measured to examine the structural and functional relationship. Correlational analyses were corrected for multiple comparisons with Bonferroni correction. Statistical analyses were performed using the statistical package SPSS program (IBM SPSS Statistics 20).

\section{Ethical considerations}

The study protocol was approved by the Ethics Committee at the Health Department of the Basque

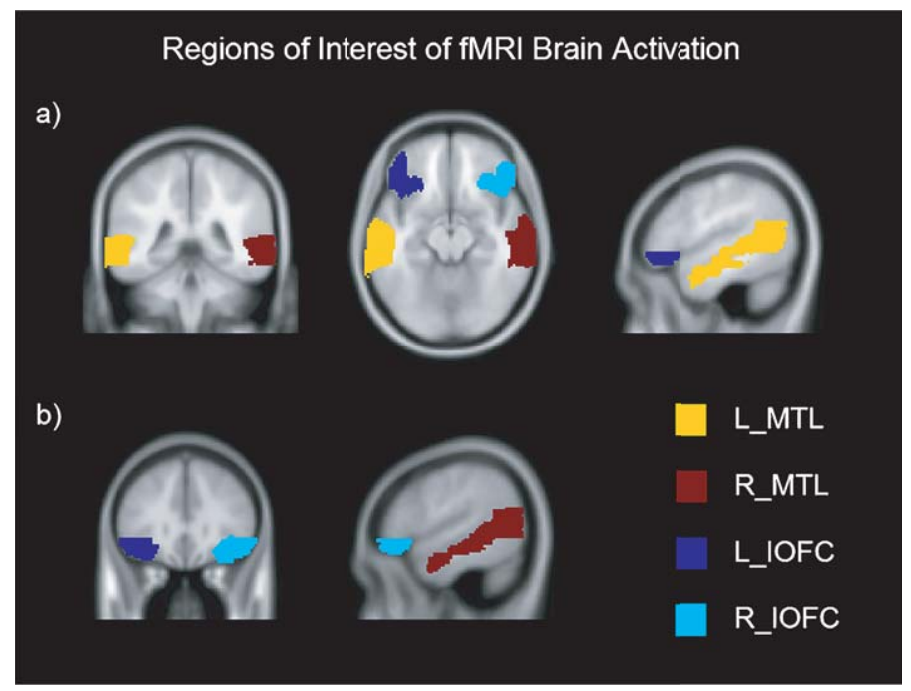

Fig. 2. Regions of Interest of fMRI brain activation in axial, coronal and sagittal view. Montreal Neurological Institutes (MNI) template coordinates for a): $\mathrm{x}=-50.2 \mathrm{y}=-40.8 \mathrm{z}=-13.5$. MNI for $\mathrm{b}$ ): $\mathrm{x}=53.7 \mathrm{y}=31 \mathrm{z}=-12.5$. L=Left; R=Right; MTL=Medial Temporal Lobe; $\mathrm{IOFC}=$ Inferior Orbitofrontal Cortex. 
Mental Health System in Spain. All subjects were volunteers and provided written informed consent prior to their participation in the study, in accordance with the Declaration of Helsinki.

\section{RESULTS}

Between groups differences in verbal memory, FA and brain activation

In the verbal memory fMRI paradigm, there were significant differences in hits $(\mathrm{U}=118 ; p=0.004)$ and false negatives $(\mathrm{U}=123 ; p=0.006)$ during the recognition fMRI task between PD patients and HC group. PD patients had more false negatives than $\mathrm{HC}$, while $\mathrm{HC}$ had more hits than the PD group (see Table 2).

There were significant differences in FA of the left PCT $(\mathrm{t}=3.046 ; p=0.004)$ and in FA of the right ACT $(\mathrm{t}=-3.314 ; p=0.002)$. PD patients showed lower FA in the right ACT but higher FA in the left PCT than HC (see Table 2). PD patients showed significant lower brain activation in the right IOFC $(\mathrm{t}=-2.583$; $p=0.013$ ) during the verbal learning memory fMRI task than HC (see Table 2).

\section{Correlations between verbal memory and FA adjusting for disease stage and duration in PD group}

No significant correlations between behavioral data from the verbal memory fMRI paradigm and selected ROIs' FA values were found in PD (see Table 3). In HC group, FA of the right PCT correlated positively with correct rejections $(r=0.729 ; p=0.003)$ and negatively with false positives $(r=-0.729 ; p=0.003)$ (see Table 3).

\section{Correlations between verbal memory and brain activation adjusting for disease stage and duration in PD group}

In PD patients, functional brain activation during the verbal recognition memory fMRI task in the left IOFC correlated positively with hits $(r=0.616$; $p<0.001)$ and negatively with false negatives $(r=-0.611 ; p<0.001)$ of the verbal memory fMRI paradigm (see Table 4). No significant correlations between behavioral data from the verbal memory fMRI paradigm and brain activation during the verbal recognition memory fMRI task were found in $\mathrm{HC}$ (see Table 4).

Table 2

Between groups differences in verbal memory paradigm, FA and brain activation

\begin{tabular}{|c|c|c|c|c|c|}
\hline & & PD & $\mathrm{HC}$ & Statistic $\mathrm{U} / \mathrm{t}^{\mathrm{a}}$ & $p$ \\
\hline \multicolumn{6}{|c|}{ Verbal memory paradigm } \\
\hline HITS & & $9.11(4.14)$ & $12.29(1.77)$ & 118 & $0.004 *$ \\
\hline $\mathrm{CR}$ & & $11.66(2.96)$ & $11.93(2.20)$ & 238 & 0.874 \\
\hline $\mathrm{FN}$ & & $5.77(4.12)$ & $2.71(1.77)$ & 123 & $0.006^{*}$ \\
\hline FP & & $3.26(2.94)$ & $3.07(2.20)$ & 236 & 0.839 \\
\hline \multicolumn{6}{|c|}{ Fractional Anisotropy } \\
\hline \multirow[t]{2}{*}{ UF } & $\mathrm{L}$ & $0.059(0.003)$ & $0.059(0.003)$ & $-0.203^{\mathrm{a}}$ & 0.840 \\
\hline & $\mathrm{R}$ & $0.059(0.003)$ & $0.060(0.003)$ & $-0.903^{\mathrm{a}}$ & 0.371 \\
\hline \multirow[t]{2}{*}{ PCT } & $\mathrm{L}$ & $0.044(0.003)$ & $0.041(0.003)$ & $3.046^{\mathrm{a}}$ & $0.004^{*}$ \\
\hline & $\mathrm{R}$ & $0.055(0.003)$ & $0.054(0.003)$ & $1.379^{\mathrm{a}}$ & 0.174 \\
\hline \multirow[t]{2}{*}{$\mathrm{ACT}$} & $\mathrm{L}$ & $0.055(0.002)$ & $0.057(0.003)$ & 173 & 0.035 \\
\hline & $\mathrm{R}$ & $0.039(0.002)$ & $0.041(0.002)$ & $-3.314^{\mathrm{a}}$ & $0.002 *$ \\
\hline \multicolumn{6}{|c|}{ Learning Brain Activation } \\
\hline \multirow[t]{2}{*}{ MTL } & $\mathrm{L}$ & $0.107(0.194)$ & $0.058(0.224)$ & $0.779^{\mathrm{a}}$ & 0.440 \\
\hline & $\mathrm{R}$ & $-0.222(0.293)$ & $-0.060(0.230)$ & 155 & 0.017 \\
\hline \multirow[t]{2}{*}{ IOFC } & $\mathrm{L}$ & $0.075(0.312)$ & $0.260(0.336)$ & $-1.880^{\mathrm{a}}$ & 0.066 \\
\hline & $\mathrm{R}$ & $0.003(0.340)$ & $0.265(0.306)$ & $-2.583^{\mathrm{a}}$ & $0.013^{*}$ \\
\hline \multicolumn{6}{|c|}{ Recognition Brain Activation } \\
\hline \multirow[t]{2}{*}{ MTL } & $\mathrm{L}$ & $0.283(0.595)$ & $0.124(0.230)$ & 188 & 0.257 \\
\hline & $\mathrm{R}$ & $0.061(0.600)$ & $0.007(0.252)$ & 201 & 0.401 \\
\hline \multirow[t]{2}{*}{ IOFC } & $\mathrm{L}$ & $-0.047(1.71)$ & $0.392(0.473)$ & 175 & 0.153 \\
\hline & $\mathrm{R}$ & $0.437(1.71)$ & $0.431(0.340)$ & 138 & 0.023 \\
\hline
\end{tabular}

Values are expressed as the mean (SD) unless otherwise noted. * Significant corrected for multiple comparisons by Bonferroni's procedure. $\mathrm{PD}=$ Parkinson's disease; $\mathrm{HC}=$ Healthy controls; $\mathrm{SD}=\mathrm{Standard}$ Deviation; $\mathrm{CR}=$ Correct Rejections; FN = False Negatives $; \mathrm{FP}=$ False Positives $; \mathrm{L}=$ Left $; \mathrm{R}=$ Right UF = Uncinate Fasciculus; $\mathrm{PCT}=$ Posterior Cingulate Tract; $\mathrm{ACT}=$ Anterior Cingulate Tract; $\mathrm{MTL}=$ Medial Temporal Lobe; $\mathrm{IOFC}=\mathrm{Inferior}$ Orbitofrontal Cortex. 
Structural-functional relationship between FA and brain activation adjusting for disease stage and duration in PD group

In PD patients, there was a significant positive correlation between brain activation in the left IOFC during

Table 3

Correlations between verbal memory paradigm and FA adjusting for disease stage and duration in PD group

\begin{tabular}{lllrrrr}
\hline & & & \multicolumn{4}{c}{ Verbal memory paradigm } \\
\cline { 3 - 7 } PD & & & HITS & \multicolumn{1}{c}{ CR } & \multicolumn{1}{c}{ FN } & \multicolumn{1}{c}{ FP } \\
\hline \multirow{4}{*}{} & UF & L & -0.129 & 0.217 & 0.110 & -0.208 \\
& & R & -0.019 & 0.264 & 0.005 & -0.246 \\
& PCT & L & -0.015 & -0.172 & -0.004 & 0.197 \\
& & R & 0.055 & 0.232 & -0.089 & -0.194 \\
& ACT & L & 0.040 & 0.089 & -0.065 & -0.079 \\
& & R & 0.257 & 0.183 & -0.277 & -0.158 \\
HC & & & & & & \\
& UF & L & 0.247 & 0.240 & -0.247 & -0.240 \\
& & R & 0.470 & 0.306 & -0.470 & -0.306 \\
& PCT & L & 0.103 & 0.671 & -0.103 & -0.671 \\
& & R & 0.086 & $0.729^{*}$ & -0.086 & $-0.729^{*}$ \\
& ACT & L & 0.438 & 0.294 & -0.438 & -0.294 \\
& & R & 0.401 & 0.224 & -0.401 & -0.224 \\
\hline
\end{tabular}

*Significant at $p<0.005$ corrected for multiple comparisons by Bonferroni's procedure. $\mathrm{PD}=$ Parkinson's disease; $\mathrm{HC}=$ Healthy controls; $\mathrm{L}=\mathrm{Left} ; \mathrm{R}=\mathrm{Right} ; \mathrm{UF}=$ Uncinate Fasciculus; $\mathrm{PCT}=$ Posterior Cingulate Tract $\mathrm{ACT}=$ Anterior Cingulate Tract; $\mathrm{CR}=$ Correct Rejections; $\mathrm{FN}=$ False Negatives; $\mathrm{FP}=$ False Positives the verbal learning memory fMRI task and FA of the right UF ( $r=0.470 ; p=0.007$ ) (see Table 5). That is, the greater the integrity of the PD patients' UF, the greater functional brain activation in the left IOFC, while they performed learning task. No significant correlations between FA and brain activation during the verbal memory fMRI tasks were found in HC (see Table 5 and Figure 3).

\section{DISCUSSION}

The present study sought to investigate the neuroanatomical $\mathrm{WM}$ and functional organization of verbal memory in PD and explored the possibilities of combining fMRI and DTI data to better understand the neural mechanisms that underlie verbal memory deficits in PD.

This study revealed significant dysfunctions in the verbal memory fMRI paradigm performance in PD patients compared to HC. Specifically in this study, PD patients had a significantly lower percentage of hits and a higher proportion of false negatives than HC during the verbal recognition memory fMRI task. The spectrum of verbal recognition alteration observed in this sample confirms previous reports that have shown that most PD patients exhibit impairments in memory $[7,9]$, and that verbal memory had the largest effect

Table 4

Correlations between verbal memory paradigm and brain activation adjusting for disease stage and duration in PD group

\begin{tabular}{|c|c|c|c|c|c|c|}
\hline & & & \multicolumn{4}{|c|}{ Verbal memory paradigm } \\
\hline & & & HITS & $\mathrm{CR}$ & FN & FP \\
\hline \multirow[t]{10}{*}{$\overline{\mathrm{PD}}$} & Learning Brain Activation & & & & & \\
\hline & MTL & $\mathrm{L}$ & 0.360 & 0.121 & -0.336 & -0.078 \\
\hline & & $\mathrm{R}$ & 0.023 & -0.030 & -0.033 & 0.062 \\
\hline & IOFC & $\mathrm{L}$ & 0.217 & 0.187 & -0.217 & -0.175 \\
\hline & & $\mathrm{R}$ & 0.397 & 0.065 & -0.394 & -0.044 \\
\hline & Recognition Brain Activation & & & & & \\
\hline & MTL & $\mathrm{L}$ & 0.449 & -0.106 & -0.449 & 0.118 \\
\hline & & $\mathrm{R}$ & -0.268 & 0.171 & 0.233 & -0.179 \\
\hline & IOFC & $\mathrm{L}$ & $0.616^{*}$ & -0.228 & $-0.611^{*}$ & 0.253 \\
\hline & & $\mathrm{R}$ & 0.288 & -0.092 & -0.309 & 0.076 \\
\hline \multirow[t]{10}{*}{$\mathrm{HC}$} & Learning Brain Activation & & & & & \\
\hline & MTL & $\mathrm{L}$ & 0.255 & -0.612 & -0.255 & 0.612 \\
\hline & & $\mathrm{R}$ & 0.088 & 0.482 & -0.088 & -0.482 \\
\hline & IOFC & $\mathrm{L}$ & 0.482 & 0.071 & -0.482 & -0.071 \\
\hline & & $\mathrm{R}$ & 0.311 & 0.059 & -0.311 & -0.059 \\
\hline & Recognition Brain Activation & & & & & \\
\hline & MTL & $\mathrm{L}$ & 0.086 & -0.264 & -0.086 & 0.264 \\
\hline & & $\mathrm{R}$ & -0.328 & 0.532 & 0.328 & -0.532 \\
\hline & IOFC & $\mathrm{L}$ & -0.247 & -0.369 & 0.247 & 0.369 \\
\hline & & $\mathrm{R}$ & -0.485 & -0.040 & 0.485 & 0.040 \\
\hline
\end{tabular}

*Significant at $p<0.004$ corrected for multiple comparisons by Bonferroni's procedure. $\mathrm{PD}=$ Parkinson's disease; $\mathrm{HC}=$ Healthy controls; $\mathrm{L}=\mathrm{Left} ; \mathrm{R}=\mathrm{Right} ; \mathrm{MTL}=$ Medial Temporal Lobe; $\mathrm{IOFC}=$ Inferior Orbitofrontal Cortex; $\mathrm{CR}=$ Correct Rejections; FN = False Negatives; FP = False Positives. 
Table 5

Structural-functional relationship between FA and brain activation adjusting for disease stage and duration in PD group

\begin{tabular}{|c|c|c|c|c|c|c|c|c|c|c|}
\hline & & & \multicolumn{4}{|c|}{ Learning } & \multicolumn{4}{|c|}{ Recognition } \\
\hline & & & \multicolumn{2}{|c|}{ MTL } & \multicolumn{2}{|c|}{ IOFC } & \multicolumn{2}{|c|}{ MTL } & \multicolumn{2}{|c|}{ IOFC } \\
\hline & & & $\mathrm{L}$ & $\mathrm{R}$ & $\mathrm{L}$ & $\mathrm{R}$ & $\mathrm{L}$ & $\mathrm{R}$ & $\mathrm{L}$ & $\mathrm{R}$ \\
\hline \multicolumn{11}{|c|}{$\mathrm{PD}$} \\
\hline & UF & $\mathrm{L}$ & 0.226 & 0.131 & 0.329 & 0.063 & -0.146 & 0.033 & 0.027 & -0.129 \\
\hline & & $\mathrm{R}$ & 0.175 & -0.103 & $0.478^{*}$ & 0.161 & -0.142 & -0.143 & 0.001 & -0.074 \\
\hline & PCT & $\mathrm{L}$ & -0.024 & 0.333 & -0.029 & 0.046 & -0.184 & 0.024 & -0.202 & -0.060 \\
\hline & & $\mathrm{R}$ & 0.132 & 0.271 & 0.300 & 0.155 & -0.134 & 0.076 & 0.090 & 0.079 \\
\hline & ACT & $\mathrm{L}$ & -0.030 & 0.072 & 0.270 & 0.185 & -0.234 & 0.026 & 0.031 & 0.305 \\
\hline & & $\mathrm{R}$ & -0.052 & 0.082 & 0.180 & 0.191 & -0.110 & -0.093 & 0.036 & 0.238 \\
\hline \multicolumn{11}{|c|}{$\mathrm{HC}$} \\
\hline & UF & $\mathrm{L}$ & 0.154 & 0.222 & 0.262 & 0.152 & 0.048 & -0.128 & -0.253 & -0.134 \\
\hline & & $\mathrm{R}$ & 0.133 & 0.288 & 0.222 & 0.185 & -0.170 & -0.191 & -0.457 & -0.356 \\
\hline & PCT & $\mathrm{L}$ & -0.283 & 0.149 & 0.382 & 0.179 & -0.241 & -0.026 & -0.273 & 0.092 \\
\hline & & $\mathrm{R}$ & 0.009 & 0.303 & 0.271 & 0.262 & 0.003 & 0.120 & -0.262 & 0.091 \\
\hline & ACT & $\mathrm{L}$ & 0.280 & 0.278 & 0.298 & 0.224 & 0.161 & -0.058 & -0.191 & -0.087 \\
\hline & & $\mathrm{R}$ & 0.368 & 0.218 & 0.292 & 0.131 & 0.200 & -0.142 & -0.067 & -0.017 \\
\hline
\end{tabular}

*Significant at $p<0.005$ corrected for multiple comparisons by Bonferroni's procedure. PD $=$ Parkinson's disease; HC $=$ Healthy controls; $\mathrm{FA}=$ Fractional Anisotropy $\mathrm{L}=\mathrm{Left} ; \mathrm{R}=$ Right $\mathrm{MTL}=$ Medial Temporal Lobe; $\mathrm{IOFC}=$ Inferior Orbitofrontal Cortex; UF = Uncinate Fasciculus; $\mathrm{PCT}=$ Posterior Cingulate Tract; $\mathrm{ACT}=$ Anterior Cingulate Tract.

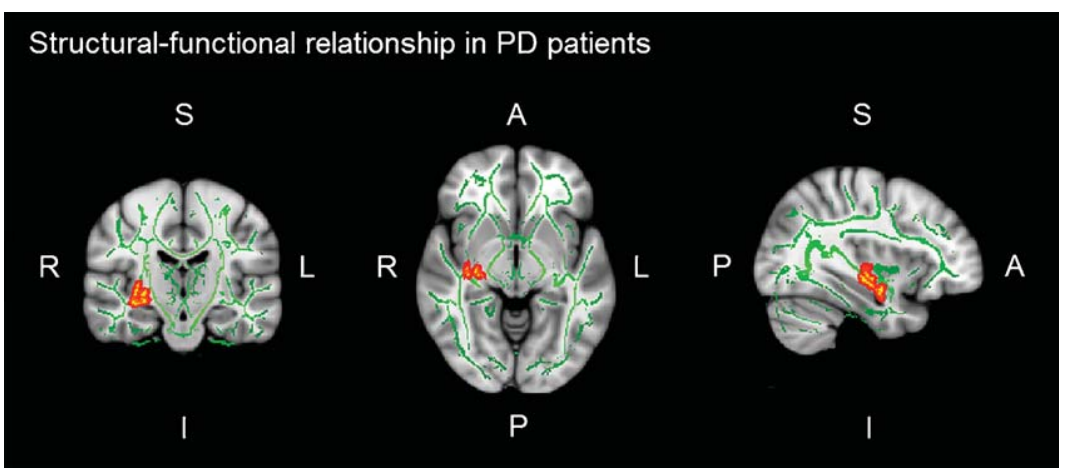

Fig. 3. Significant voxel-wise correlations (red) between fractional anisotropy (FA) of the right uncinate fasciculus (UF) and brain activation in the left orbitofrontal cortex (IOFC) during verbal learning memory fMRI task. Montreal Neurological Institutes (MNI) template coordinates: $x=36 y=-5 z=18$.

size compared with other cognitive domains [8]. In a study by Ibarretxe-Bilbao and colleagues [43], a similar verbal recognition memory fMRI paradigm was used in early PD patients, and there were no significant behavioral differences in the recognition task, although there was a trend toward more false positive errors in PD patients. These results confirm the finding that recognition memory dysfunction in the early stages of PD is much more extensive than was previously thought $[15,16]$.

Regarding WM microstructural changes, in this study, PD patients had less FA in the right ACT compared to HC, but they had more FA in the left PCT. Similar results have been found to demonstrate that FA reduction of anterior cingulum is present in $\mathrm{PD}$
$[36,60]$, but the higher FA value of the left PCT in non-demented PD patients could be explained with studies that reveal differences in posterior cingulum only between PD patients with dementia and controls [36]. In functional brain activation results, this study revealed a significant difference in the right IOFC during the verbal learning memory fMRI task between $\mathrm{PD}$ and $\mathrm{HC}$ groups. HC group showed higher activation than PD patients in the learning task. In aging, the relation of right frontal activation to verbal memory encoding occurred only in individuals with good memory performance [61]. According to previous literature $[12,43]$, PD patients showed lower brain activation in this region compared with $\mathrm{HC}$ during a similar recognition memory fMRI paradigm. Furthermore, in a verbal 
encoding study, high performing older adults exhibited activation in right inferior prefrontal cortex [61].

Few studies have investigated the neuroanatomical correlates of memory impairment in PD using the FA index $[30,33]$. There is more literature concerning global cognitive performance correlates in PD [29, $30,36,37]$. In this study, contrary to our hypothesis, there were not specific correlations of FA values with data of the verbal recognition memory fMRI task in PD patients. In some studies, an association has been identified between increased DTI mean diffusivity and decreased learning and memory domain scores in anterior WM tracts in PD patients [30, 33]. Nevertheless, in this research, HC showed a significant correlation between FA of the right PCT and correct rejections and false positives. That is, the greater FA in the right $\mathrm{PCT}$, the greater performance in verbal recognition memory. Moreover, literature suggests that the PCT is critical for strategic memory process related to successful encoding [50], which is a core process in subsequent recognition memory.

Regarding neurofunctional correlates in PD, our study revealed a significant correlation between brain activation of the left IOFC during the verbal recognition fMRI task and verbal memory impairment, suggesting that the deficit in verbal memory performance during the fMRI paradigm could be influenced by lower brain activation in orbitofrontal cortices during the recognition memory fMRI task. These results are in line with previous literature and some fMRI studies in PD have also revealed reduced recruitment of the recognition memory network, including decreased activation in the orbitofrontal cortices and in the medial temporal areas [12, 43].

Previous studies have been conducted to our understanding of cognitive functioning in PD using DTI [29, 30, 32-34, 37, 60, 62] and fMRI [12, 38, 40, 42, 43] separately, but little is known about combination of both. The third objective of this study was to investigate the relationship between neuroanatomical and neurofunctional verbal memory correlates in PD to better understand the neural mechanisms and functional organization that underlie verbal memory deficits in PD. In this study, a structure-function relationship was found between WM microstructure FA and brain activation during the verbal learning memory fMRI task in PD. The PD patients' FA of the right UF correlated with brain activation of the left IOFC during the verbal learning memory fMRI task. The UF is a bidirectional WM tract that connects orbitofrontal cortex with temporal lobes, and its disruption may cause problems in the acquisition of certain types of learning and memory [49, 57, 63]. In other studies, the UF also correlated with learning errors suggesting that lower FA of the UF was related with more learning errors [52]. Moreover, it is important to note that the UF projected to the orbitofrontal cortex supports error-related processing in interaction with anterior cingulate and lateral prefrontal cortex [58].

Although it is known that verbal material is strongly associated with left hemispheres, these bilateral differences and relationships could be explained by age-associated reduced laterality [24]. There has been debate about how age-associated reduction in asymmetric activation is interpreted [64, 65]. fMRI studies of memory performance in older adults have shown that decreased laterality in frontal activation refers to a reduction of the difference between activation in right and left regions relative to young adults $[61,65]$. Moreover, not only less-lateralized frontal activation is present, but older adults with high memory ability showed more right frontal lobe activation [61]. One argument is compensation, suggesting that recruiting the contralateral hemisphere is an adaptive response to age-related declines in brain integrity $[65,66]$.

Taken all together, the lower performance in verbal memory in PD is related to the lower brain activation in orbitofrontal cortices during the verbal recognition memory fMRI task, but moreover, the orbitofrontal cortices that correlated in the verbal recognition memory fMRI task are the same regions that correlated with FA of the UF during the verbal learning memory fMRI task. These results suggest that fronto-temporal involvement in the learning process affects subsequent recognition memory impairment in PD [52]. Consistent with the findings of Bronnick et al., [18] we observed a clear influence of learning in PD patients, supporting the idea that learning is an essential part of the memory process [14] as shown by the relationship between brain activation during the learning task and the FA of the UF.

Some limitations of the study must be considered. Our sample was small and controlling for learning trials is necessary. Some studies in other neurological samples, including subjects with multiple sclerosis $[67,68]$ and those with traumatic brain injury [69], have demonstrated that when a method controlling for additional trials is applied, the quality of coding can be improved. Although in our study learning trials were not controlled, results suggest that acquisition or prior learning is the key factor for subsequent recognition performance. Future analysis of the relationship 
between the individual differences in FA and brain activation parameters derived from anatomically defined ROIs may help further constrain the roles of both WM microstructures and the cortical regions of focal activation across several cognitive domains in PD.

In conclusion, the present study represents a first step toward integrating functional and structural data in the domain of verbal memory in PD. To our knowledge, this is the first study to show the neural substrate of verbal memory combining DTI and fMRI techniques. We postulate that impaired recognition might reflect deficient memory consolidation that is at least partly due to the influence of the learning process and to underlying orbitofrontal and temporal degeneration. We have found evidence that supports previously described impairments in verbal memory, FA reduction, and lower brain activation in PD patients. Greater integrity of the UF may support memory functions that can take advantage of cognitive functions mediated by the IOFC. The results of these analyses are novel insofar as they reveal that deficits in the verbal memory in $\mathrm{PD}$, rather than being solely accompanied by functional brain activation dysfunction, have specific relationship with structural correlates related to WM microstructural integrity.

\section{FUNDING AGENCIES}

This study was supported by the Health Department of the Basque Government (2011111117; to Dr. Naroa Ibarretxe-Bilbao) and the Spanish Ministry of Economy and Competitiveness (PSI2012-32441; to Dr. Naroa Ibarretxe-Bilbao).

\section{ACKNOWLEDGMENTS}

We would like to thank ASPARBI and all of the participants involved in the study for making this research possible.

\section{CONFLICTS OF INTEREST}

The authors have no conflict of interest to report.

\section{REFERENCES}

[1] Samii A, Nutt JG, \& Ransom BR (2004) Parkinson's disease. Lancet, 363, 1783-1793.

[2] Halliday G, Hely M, Reid W, \& Morris J (2008) The progression of pathology in longitudinally followed patients with Parkinson's disease. Acta Neuropathol, 115, 409-415.
[3] Hely MA, Reid WG, Adena MA, Halliday GM, \& Morris JG (2008) The Sydney multicenter study of Parkinson's disease: The inevitability of dementia at 20 years. Mov Disord, 23, 837-844.

[4] Aarsland D, Bronnick K, Williams-Gray C, Weintraub D, Marder K, Kulisevsky J, Burn D, Barone P, Pagonabarraga J, Allcock L, Santangelo G, Foltynie T, Janvin C, Larsen JP, Barker RA, \& Emre M (2010) Mild cognitive impairment in Parkinson disease: A multicenter pooled analysis. Neurology, 75, 1062-1069.

[5] Barone P, Aarsland D, Burn D, Emre M, Kulisevsky J, \& Weintraub D (2011) Cognitive impairment in nondemented Parkinson's disease. Mov Disord, 26, 2483-2495.

[6] Foltynie T, Brayne CE, Robbins TW, \& Barker RA (2004) The cognitive ability of an incident cohort of Parkinson's patients in the UK. The CamPaIGN study. Brain, 127, 550-560.

[7] Muslimovic D, Post B, Speelman JD, \& Schmand B (2005) Cognitive profile of patients with newly diagnosed Parkinson disease. Neurology, 65, 1239-1245.

[8] Aarsland D, Brønnick K, Larsen JP, Tysnes OB, Alves G, \& Group NPS (2009) Cognitive impairment in incident, untreated Parkinson disease: The Norwegian ParkWest study. Neurology, 72, 1121-1126.

[9] Elgh E, Domellof M, Linder J, Edstrom M, Stenlund H, \& Forsgren L (2009) Cognitive function in early Parkinson's disease: A population-based study. Eur J Neurol, 16, 12781284.

[10] Higginson CI, King DS, Levine D, Wheelock VL, Khamphay NO, \& Sigvardt KA (2003) The relationship between executive function and verbal memory in Parkinson's disease. Brain Cogn, 52, 343-352.

[11] Bohlhalter S, Abela E, Weniger D, \& Weder B (2009) Impaired verbal memory in Parkinson disease: Relationship to prefrontal dysfunction and somatosensory discrimination. Behav Brain Funct, 5, 49.

[12] Segura B, Ibarretxe-Bilbao N, Sala-Llonch R, Baggio HC, Marti MJ, Valldeoriola F, Vendrell P, Bargallo N, Tolosa E, \& Junque C (2013) Progressive changes in a recognition memory network in Parkinson's disease. J Neurol Neurosurg Psychiatry, 84, 370-378.

[13] Beyer MK, Bronnick KS, Hwang KS, Bergsland N, Tysnes OB, Larsen JP, Thompson PM, Somme JH, \& Apostolova LG (2013) Verbal memory is associated with structural hippocampal changes in newly diagnosed Parkinson's disease. J Neurol Neurosurg Psychiatry, 84, 23-28.

[14] Chiaravalloti ND, Ibarretxe-Bilbao N, DeLuca J, Rusu O, Pena J, Garcia-Gorostiaga I, \& Ojeda N (2014) The source of the memory impairment in Parkinson's disease: Acquisition versus retrieval. Mov Disord, 29, 765-771.

[15] Whittington CJ, Podd J, \& Kan MM (2000) Recognition memory impairment in Parkinson's disease: Power and metaanalyses. Neuropsychology, 14, 233-246.

[16] Higginson CI, Wheelock VL, Carroll KE, \& Sigvardt KA (2005) Recognition memory in Parkinson's disease with and without dementia: Evidence inconsistent with the retrieval deficit hypothesis. J Clin Exp Neuropsychol, 27, 516-528.

[17] Breen EK (1993) Recall and recognition memory in Parkinson's disease. Cortex, 29, 91-102.

[18] Bronnick K, Alves G, Aarsland D, Tysnes OB, \& Larsen JP (2011) Verbal memory in drug-naive, newly diagnosed Parkinson's disease. The retrieval deficit hypothesis revisited. Neuropsychology, 25, 114-124.

[19] Whittington CJ, Podd J, \& Stewart-Williams S (2006) Memory deficits in Parkinson's disease. J Clin Exp Neuropsychol, 28, 738-754. 
[20] Minamoto H, Tachibana H, Sugita M, \& Okita T (2001) Recognition memory in normal aging and Parkinson's disease: Behavioral and electrophysiologic measures. Cogn Brain Res, 11, 23-32.

[21] Weintraub D, Moberg PJ, Culbertson WC, Duda JE, \& Stern MB (2004) Evidence for impaired encoding and retrieval memory profiles in Parkinson disease. Cogn Behav Neurol, 17, 195-200.

[22] Ivory S-J, Knight R, Longmore B, \& Caradoc-Davies T (1999) Verbal memory in non-demented patients withidiopathic Parkinson's disease. Neuropsychologia, 37, 817-828.

[23] Taylor AE, Saint-Cyr J, \& Lang A (1990) Memory and learning in early Parkinson's disease: Evidence for a "frontal lobe syndrome". Brain Cogn, 13, 211-232.

[24] Rosen AC, Gabrieli JD, Stoub T, Prull MW, O’Hara R, \& Yesavage J (2005) Relating medial temporal lobe volume to frontal fMRI activation for memory encoding in older adults. Cortex, 41, 595-602.

[25] Aggleton JP, \& Brown MW (2006) Interleaving brain systems for episodic and recognition memory. Trends Cogn Sci, 10 , 455-463.

[26] Diana RA, Yonelinas AP, \& Ranganath C (2007) Imaging recollection and familiarity in the medial temporal lobe: A three-component model. Trends Cogn Sci, 11, 379-386.

[27] Yonelinas AP, \& Levy BJ (2002) Dissociating familiarity from recollection in human recognition memory: Different rates of forgetting over short retention intervals. Psychon Bull Rev, 9, 575-582.

[28] Yonelinas AP, Otten LJ, Shaw KN, \& Rugg MD (2005) Separating the brain regions involved in recollection and familiarity in recognition memory. $J$ Neurosci, 25, 3002-3008.

[29] Cochrane CJ, \& Ebmeier KP (2013) Diffusion tensor imaging in parkinsonian syndromes A systematic review and metaanalysis. Neurology, 80, 857-864.

[30] Melzer TR, Watts R, MacAskill MR, Pitcher TL, Livingston L, Keenan RJ, Dalrymple-Alford JC, \& Anderson TJ (2013) White matter microstructure deteriorates across cognitive stages in Parkinson disease. Neurology, 80, 1841-1849.

[31] Matsui H, Nishinaka K, Oda M, Niikawa H, Komatsu K, Kubori T, \& Udaka F (2007) Wisconsin Card Sorting Test in Parkinson's disease: Diffusion tensor imaging. Acta Neurol Scand, 116, 108-112.

[32] Vaillancourt D, Spraker M, Prodoehl J, Abraham I, Corcos D, Zhou X, Comella C, \& Little D (2009) High-resolution diffusion tensor imaging in the substantia nigra of de novo Parkinson disease. Neurology, 72, 1378-1384.

[33] Zheng Z, Shemmassian S, Wijekoon C, Kim W, Bookheimer SY, \& Pouratian N (2014) DTI correlates of distinct cognitive impairments in Parkinson's disease. Hum Brain Mapp, 35, $1325-1333$.

[34] Theilmann RJ, Reed JD, Song DD, Huang MX, Lee RR, Litvan I, \& Harrington DL (2013) White-matter changes correlate with cognitive functioning in Parkinson's disease. Front Neurol, 4, 37.

[35] Bohnen NI, \& Albin RL (2011) White matter lesions in Parkinson disease. Nat Rev Neurol, 7, 229-236.

[36] Kamagata K, Motoi Y, Abe O, Shimoji K, Hori M, Nakanishi A, Sano T, Kuwatsuru R, Aoki S, \& Hattori N (2012) White matter alteration of the cingulum in Parkinson disease with and without dementia: Evaluation by diffusion tensor tractspecific analysis. AJNR Am J Neuroradiol, 33, 890-895.

[37] Hattori T, Orimo S, Aoki S, Ito K, Abe O, Amano A, Sato R, Sakai K, \& Mizusawa H (2012) Cognitive status correlates with white matter alteration in Parkinson's disease. Hum Brain Mapp, 33, 727-739.

[38] Rottschy C, Kleiman A, Dogan I, Langner R, Mirzazade S, Kronenbuerger M, Werner C, Shah NJ, Schulz JB, Eickhoff SB, \& Reetz K (2013) Diminished activation of motor working-memory networks in Parkinson's disease. PLoS One, 8, e61786.

[39] Wu T, \& Hallett M (2005) A functional MRI study of automatic movements in patients with Parkinson's disease. Brain, 128, 2250-2259.

[40] Nagano-Saito A, Habak C, Mejía-Constaín B, Degroot C, Monetta L, Jubault T, Bedetti C, Lafontaine A-L, Chouinard S, \& Soland V (2014) Effect of mild cognitive impairment on the patterns of neural activity in early Parkinson's disease. Neurobiol Aging, 35, 223-231.

[41] Lewis SJ, Dove A, Robbins TW, Barker RA, \& Owen AM (2003) Cognitive impairments in early Parkinson's disease are accompanied by reductions in activity in frontostriatal neural circuitry. J Neurosci, 23, 6351-6356.

[42] van Eimeren T, Monchi O, Ballanger B, \& Strafella AP (2009) Dysfunction of the default mode network in Parkinson disease: A functional magnetic resonance imaging study. Arch Neurol, 66, 877-883.

[43] Ibarretxe-Bilbao N, Zarei M, Junque C, Marti MJ, Segura B, Vendrell P, Valldeoriola F, Bargallo N, \& Tolosa E (2011) Dysfunctions of cerebral networks precede recognition memory deficits in early Parkinson's disease. Neuroimage, 57, 589-597.

[44] Schendan HE, Tinaz S, Maher SM, \& Stern CE (2013) Frontostriatal and mediotemporal lobe contributions to implicit higher-order spatial sequence learning declines in aging and Parkinson's disease. Behav Neurosci, 127, 204.

[45] Tomlinson CL, Stowe R, Patel S, Rick C, Gray R, \& Clarke CE (2010) Systematic review of levodopa dose equivalency reporting in Parkinson's disease. Mov Disord, 25, 2649-2653.

[46] Marsolek CJ, Kosslyn SM, \& Squire LR (1992) Form-specific visual priming in the right cerebral hemisphere. J Exp Psychol Learn Mem Cogn, 18, 492.

[47] Jenkinson M, Beckmann CF, Behrens TE, Woolrich MW, \& Smith SM (2012) FSL. Neuroimage, 62, 782-790.

[48] Smith SM, Jenkinson M, Woolrich MW, Beckmann CF, Behrens TE, Johansen-Berg H, Bannister PR, De Luca M, Drobnjak I, Flitney DE, Niazy RK, Saunders J, Vickers J, Zhang Y, De Stefano N, Brady JM, \& Matthews PM (2004) Advances in functional and structural MR image analysis and implementation as FSL. Neuroimage, 23(Suppl 1), S208S219.

[49] Von Der Heide RJ, Skipper LM, Klobusicky E, \& Olson IR (2013) Dissecting the uncinate fasciculus: Disorders, controversies and a hypothesis. Brain 136(Pt 6) 16921707.

[50] Daselaar SM, Prince SE, Dennis NA, Hayes SM, Kim H, \& Cabeza R (2009) Posterior midline and ventral parietal activity is associated with retrieval success and encoding failure. Front Hum Neurosci, 3, 13.

[51] Vogt BA, \& Laureys S (2005) Posterior cingulate, precuneal and retrosplenial cortices: Cytology and components of the neural network correlates of consciousness. Prog Brain Res, 150, 205-217.

[52] Metzler-Baddeley C, Jones DK, Belaroussi B, Aggleton JP, \& O'Sullivan MJ (2011) Frontotemporal connections in episodic memory and aging: A diffusion MRI tractography study. J Neurosci, 31, 13236-13245. 
[53] Beauchamp MH, Dagher A, Panisset M, \& Doyon J (2008) Neural substrates of cognitive skill learning in Parkinson's disease. Brain Cogn, 68, 134-143.

[54] Hua K, Zhang J, Wakana S, Jiang H, Li X, Reich DS, Calabresi PA, Pekar JJ, van Zijl PC, \& Mori S (2008) Tract probability maps in stereotaxic spaces: Analyses of white matter anatomy and tract-specific quantification. Neuroimage, 39, 336-347.

[55] Tzourio-Mazoyer N, Landeau B, Papathanassiou D, Crivello F, Etard O, Delcroix N, Mazoyer B, \& Joliot M (2002) Automated anatomical labeling of activations in SPM using a macroscopic anatomical parcellation of the MNI MRI singlesubject brain. Neuroimage, 15, 273-289.

[56] Brett M, Anton J-L, Valabregue R, \& Poline J-B (2002) Region of interest analysis using the MarsBar toolbox for SPM 99. Neuroimage, 16, S497.

[57] Miller EK, \& Cohen JD (2001) An integrative theory of prefrontal cortex function. Ann Rev Neurosci, 24, 167-202.

[58] Turken AU, \& Swick D (2008) The effect of orbitofrontal lesions on the error-related negativity. Neurosci Lett, 441, 7-10.

[59] Ebuh G, \& Oyeka I (2012) A Nonparametric Method for Estimating Partial Correlation Coefficient. J Biom Biostat, 3, 2 .

[60] Gattellaro G, Minati L, Grisoli M, Mariani C, Carella F, Osio M, Ciceri E, Albanese A, \& Bruzzone MG (2009) White matter involvement in idiopathic Parkinson disease: A diffusion tensor imaging study. AJNR Am J Neuroradiol, 30, 1222-1226.

[61] Rosen AC, Prull MW, O'Hara R, Race EA, Desmond JE, Glover GH, Yesavage JA, \& Gabrieli JD (2002) Variable effects of aging on frontal lobe contributions to memory. Neuroreport, 13, 2425-2428.

[62] Kamagata K, Motoi Y, Tomiyama H, Abe O, Ito K, Shimoji K, Suzuki M, Hori M, Nakanishi A, Sano T, Kuwatsuru R, Sasai K, Aoki S, \& Hattori N (2013) Relationship between cognitive impairment and white-matter alteration in Parkinson's disease with dementia: Tract-based spatial statistics and tract-specific analysis. Eur Radiol, 23, 1946-1955.

[63] Schmahmann JD, \& Pandya DN (2007) The complex history of the fronto-occipital fasciculus. J Hist Neurosci, 16, 362377.

[64] Buckner RL, Logan JM (2002) Frontal contributions to episodic memory encoding in the young and elderly, Psychology Press.

[65] Cabeza R, Anderson ND, Locantore JK, \& McIntosh AR (2002) Aging gracefully: Compensatory brain activity in high-performing older adults. Neuroimage, 17, 1394-1402.

[66] Persson J, Nyberg L, Lind J, Larsson A, Nilsson L-G, Ingvar M, \& Buckner RL (2006) Structure-function correlates of cognitive decline in aging. Cereb Cortex, 16, 907-915.

[67] DeLuca J, Barbieri-Berger S, \& Johnson SK (1994) The nature of memory impairments in multiple sclerosis: Acquisition versus retrieval. J Clin Exp Neuropsychol, 16, 183-189.

[68] Deluca J, Leavitt VM, Chiaravalloti N, \& Wylie G (2013) Memory impairment in multiple sclerosis is due to a core deficit in initial learning. J Neurol, 260, 2491-2496.

[69] DeLuca J, Schultheis MT, Madigan NK, Christodoulou C, \& Averill A (2000) Acquisition versus retrieval deficits in traumatic brain injury: Implications for memory rehabilitation. Arch Phys Med Rehabil, 81, 1327-1333. 